\title{
O COMPORTAMENTO DE LEITURA DE CRIANÇAS E ADOLESCENTES, SEGUNDO A VISÃO DAS MÃES
}

\author{
Patricia Leila dos Santos* \\ Zélia Maria Mendes Biasoli Alves**
}

\section{RESUMO}

Esta pesquisa foi estruturada visando descrever qual a visão que adultos socializadores têm do comportamento de leitura das crianças e adolescentes, incluindo: o que eles lêem, os motivos que levam a essa atividade, a participação do ambiente.

Para tanto, entrevistaram-se 45 mães de crianças e adolescentes que frequentavam da pré-escola à $8^{\mathrm{a}}$ série, segundo o Roteiro para Investigação do Comportamento de Leitura. As entrevistas foram realizadas nas residências dos sujeitos, gravadas e, posteriormente, transcritas na íntegra e os dados qualitativamente analisados.

A análise dos relatos mostra que: 1) De forma geral, crianças e adolescentes lêem, na maioria das vezes cumprindo exigências escolares; sua leitura produz outras atividades, que incluem o contar histórias, fazer comentários e pedir ajuda para tirar dúvidas; os livros infanto-juvenis e gibis são os materiais que mais se destacam. 2) A família costuma incentivar a leitura de diferentes maneiras, como ler junto ou fornecer e indicar livros, revistas, etc.

Discute-se a participação da família e da escola no processo de leitura das crianças e adolescentes e a influência da atividade no processo de socialização.

\footnotetext{
* Mestre pelo Programa de Pós-Graduação em Educação do CECH da Universidade Federal de São Carlos.

** Professora Doutora do Departamento de Psicologia e Educação da Faculdade de Filosofia, Ciências e Letras de Ribeirão Preto, USP.
} 


\section{INTRODUÇÃO}

"Talvez não haja na nossa infância dias que tenhamos vivido tão plenamente como aqueles que pensamos ter deixado passar sem vivê-los, aqueles que passamos na companhia de um livro preferido (...)"

(Proust, 1991, p.9)

O comportamento de leitura é parte integrante das sociedades modernas, que investem cada vez mais na produção de materiais e em programas de estímulo ao hábito de ler.

Há muitos e diferentes motivos que levam à idéia de que a leitura é necessária: há a preocupação pedagógica de ensinar a ler e escrever para que o indivíduo possa ser capaz de conseguir as informações de que precisa de forma independente de outras pessoas ou da escola; mas há também o ideal de se formar indivíduos conscientes e informados e que tenham a possibilidade de modificar sua própria realidade.

A intenção de conhecer o comportamento de leitura de crianças e adolescentes é fruto do interesse em saber o que o conteúdo dos livros infanto-juvenis transmite para esse público.

O estudo da literatura sobre o assunto mostrou diferentes aspectos da questão. Há autores preocupados com o desenvolvimento do hábito de ler (Silva, 1986; Wornicov, 1986; Perrotti, 1990), outros, com os materiais disponíveis para crianças e adolescentes (Zilberman \& Lajolo, 1986; Abramovich, 1990; Carvalho, s/d) e, ainda, há quem fale da influência da leitura no processo de socialização do indivíduo (Abramovich, 1983; Cadermatori, 1987; Cunha, 1993).

Escolas, educadores, pais e editoras têm se preocupado de forma crescente em desenvolver o hábito de leitura nas gerações mais novas, e, nesse sentido, por vezes, trazem a idéia de que existe uma crise de leitura caracterizada pelo pouco consumo de livros, pela falta de envolvimento com o texto e pelo abandono das bibliotecas.

No entanto, o conhecimento de como é a leitura de crianças e adolescentes deveria anteceder a essas discussões. Assim, este trabalho vem com a proposta de buscar respostas para questões tais como: qual a visão que os 
adultos socializadores têm sobre a leitura de crianças e adolescentes - eles lêem? Por quê? Como? Quê elementos do ambiente estariam influenciando este comportamento?

\section{MÉTODO}

\section{Material}

Para levar a efeito o trabalho, optou-se pela entrevista semi-estruturada como estratégia de coleta de dados, considerando-se sua adequação na obtenção de informações sobre o comportamento atual das crianças e adolescentes, as atitudes e valores subjacentes ao mesmo, num discurso mais livre que permitiu ao pesquisador explorar o tema a partir da própria dinâmica do entrevistado.

Foi elaborado e testado um roteiro de entrevista a partir de núcleos de interesse com relação ao comportamento de leitura e literatura infantojuvenil, denominado RICOL (Roteiro para Investigação do Comportamento de Leitura), que ficou estruturado da seguinte forma:

I. Comportamento dos pais: investigando como foi a leitura dos pais desde a infância e como ela acontece hoje - eles lêem? Por quê? Que tipo de material? Existem exigências quanto ao ambiente de leitura (lê em qualquer lugar ou precisa de silêncio, tranquilidade, etc)?

II. Comportamento da criança: ela lê? Por quê? Que tipo de material? Existem exigências quanto ao ambiente de leitura? A atividade provoca outros comportamentos? Quais?

III. Influência externa: escola; amigos; parentes; televisão;

IV. Determinação do processo: seleção do material; meios de acesso; incentivo;

V. Avaliação ou julgamento da atividade: utilidade da leitura; expectativas.

Ao final da entrevista solicitava-se às mães que fornecessem informaçōes sobre quais os livros que a criança/adolescente focalizado tivesse lido.

Além do RICOL, foi utilizado um gravador portátil com microfone embutido, 45 fitas cassete ( 60 minutos cada), folhas de papel sulfite e caneta para 
anotação dos dados de caracterização do sujeito e das listas de livros, folhas de papel almaço, lápis e borracha para a transcrição e organização das entrevistas.

\section{Sujeitos}

Fizeram parte da amostra mães de filhos que frequentavam da pré-escola (início da alfabetização) até $8^{a}$ série (fim do $1^{9}$ grau), estabelecendo-se um número de 5 sujeitos por série (num total de 45 mães).

O contato com essas mães foi realizado através das escolas e, posteriormente, por indicações de alguns sujeitos. Os dados por sexo e idade das crianças/adolescentes, acham-se na tabela 1.

Tabela 1. Distribuição das crianças e adolescentes, cujas mães foram entrevistadas na pesquisa, em função da série frequentada e do sexo.

\begin{tabular}{|c|c|c|c|c|c|c|c|c|c|c|}
\hline $\begin{array}{l}\text { ISEFI } \\
\text { sexol }\end{array}$ & pré & $1 \mathrm{a}$. & $2 a$ & 3a. & $4 a$ & $5 a$ & $6 a$ & $7 a$ & $8 a$ & Tota \\
\hline$M$ & 4 & 1 & 1 & 3 & 4 & 2 & 1 & 2 & 2 & 20 \\
\hline $\mathbf{F}$ & 1 & 4 & 4 & 2 & 1 & 3 & 4 & 3 & 3 & 25 \\
\hline Total & 5 & 5 & 5 & 5 & 5 & 5 & 5 & 5 & 5 & 45. \\
\hline
\end{tabular}

Pela tabela observa-se que 55,5\% dos filhos focalizados nas entrevistas são do sexo feminino e 44,5\% do masculino. As idades variavam de 6 a 15 anos. entrevistadas.

A tabela 2 traz a distribuição das características das mães 
Tabela 2. Distribuição das características das mães, em funçầo do tipo de atividade profissional, nível de escolaridade e faixa etária.

profissoes

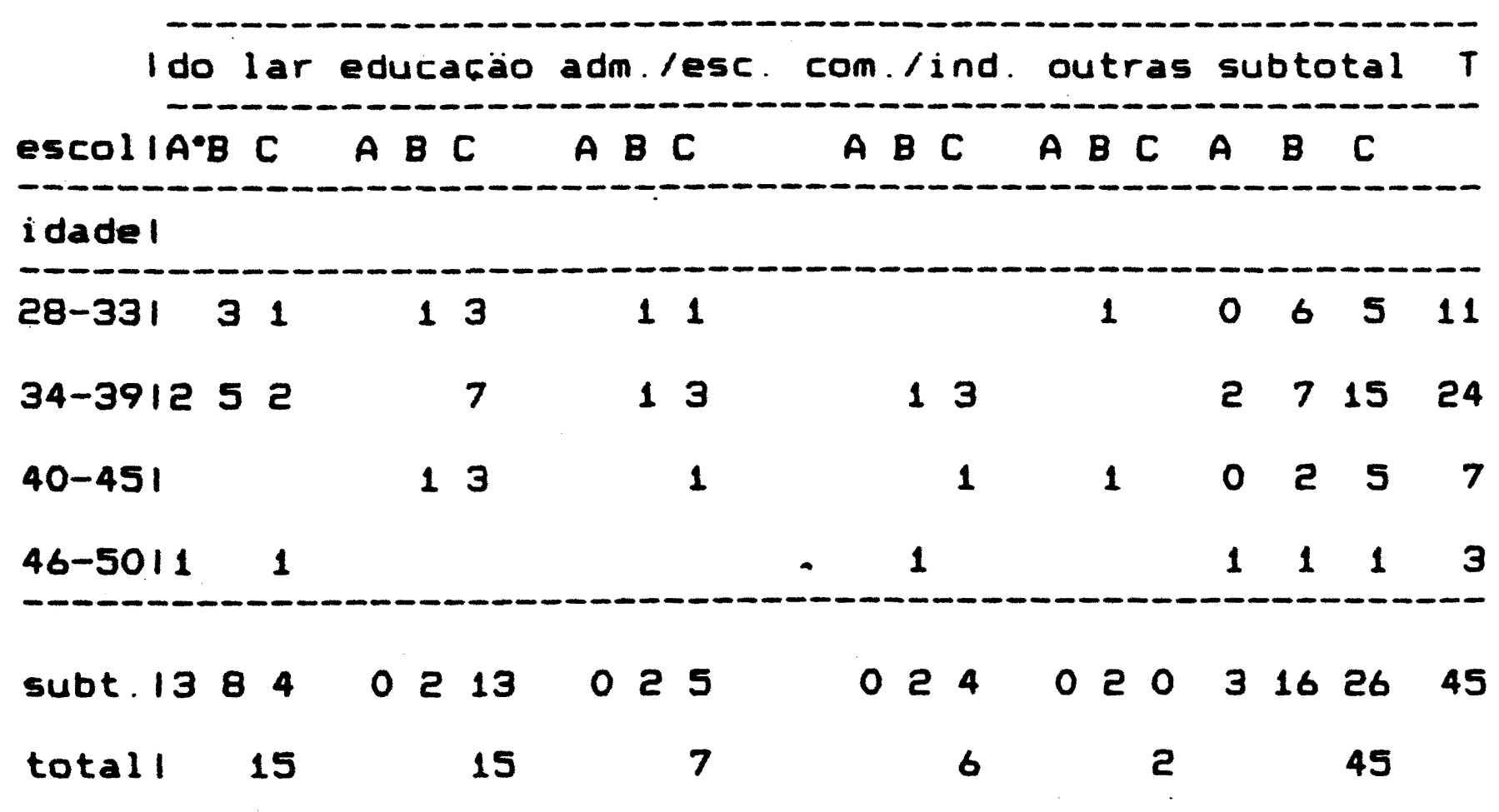
prof. - atividade profissional (do lar; educacäo; administracäo lescritório; comércio/indústrial.

escol. - nivel de escolaridade: A - 10 grau;

B - 20 grau;

C - 30 grau.

* inclui mäes que näo completaram o 10 grau. idade - faixa etária (em anos).

As mães tinham entre 28 e 50 anos (predominantemente entre 28 e 39 anos - 78\%). Conforme mostra a tabela 2, 15 (33\%) não trabalhavam fora e destas, $53 \%$ tinha o $2^{2}$ grau completo e $27 \%$ era de nível universitário. Complementarmente, $67 \%$ trabalhava fora, sendo que $50 \%$ delas em atividades 
ligadas à escola ou educação.1 ${ }^{1}$ Deste grupo, $73 \%$ tinha nível universitário e o restante, $2^{\circ}$ grau completo.

\section{Procedimento}

Os sujeitos foram contactados e entrevistados em sua residência. $O$ pesquisador se apresentava, explicava os objetivos do trabalho, esclarecia dúvidas, orientava sobre o caráter sigiloso dos dados e solicitava autorização para gravar.

As entrevistas foram gravadas, posteriormente transcritas, na íntegra e segundo o linguajar de cada sujeito.

\section{RESULTADOS}

As entrevistas tiveram uma duração média de $\mathbf{5 0}$ minutos e os dados foram qualitativamente analisados segundo o modelo proposto por Biasoli-Alves e Dias da Silva (1992).

\section{O comportamento de leitura}

A análise mostrou, inicialmente, que há três grupos de idade em função dos interesses e participação na escolha do material: o primeiro de crianças de pré-escola, $1^{\mathrm{a}}$ e $2^{\mathrm{a}}$ séries (de 6 a 8 anos de idade aproximadamente); o

1. As profissões foram agrupadas em tipos de atividades profissionais, de acordo com áreas de atuaçăo, para facilitar a organização dos dadós, tendo $\mathrm{em}$ vista a grande variedade das mesmas. A classificaçăo final é resultado do trabalho de dois juízes. 
segundo de crianças de $3^{a}, 4^{a}$ e $5^{a}$ séries ( 9 a 11 anos) e o terceiro com adolescentes de $6^{a}, 7^{a}$ e $8^{a}$ séries ( 12 a 15 anos).

\subsection{A leitura de crianças de 6 a 8 anos de idade}

A análise das informaçōes fornecidas pelas mães das crianças que frequentavam da pré-escola à $2^{\mathfrak{a}}$ série evidencia que elas lêem ou mantêm contato com materiais de leitura, e para a maioria dessa parcela da amostra (53\%) isto ocorre com frequência, sendo claro o interesse e envolvimento na atividade, sugerindo que há prazer.

"Ele é apaixonado pela leitura (...) Tudo ele quer ler (...) o contato com o livrinho, ou com outro tipo de leitura é muito prazeroso (...)"

"Ela se interessa muito por leitura (...) toda vez que a tia dá o livro prá comprar, ela quer ler no mesmo dia. Aí, ela lé uma; lê duas (...) ela le tanto que até perturba (...) a gente nota que ela é interessada (...) ela gosta muito (...)"

Além disso, diferentes tipos de material atraem a atenção dessas crianças: livros infanto-juvenis (100\%), gibis (87\%), livros didáticos $(47 \%)$, revistas (33\%), jornais (27\%), jornal infantil, mapas, álbuns de figurinha, jogos de perguntas e respostas (7\% cada).

"(...) você já vê ele pegando assim, até gibi (...)"

É interessante observar que a leitura costuma desencadear outros comportamentos, muitas vezes caracterizados por uma aproximação social da criança com os progenitores, com os companheiros: contam a história (60\%); comentam (33\%); pedem ajuda para continuar a leitura ou para tirar dúvidas (27\%); desenham (27\%); brincam (27\%); lêem para outras pessoas um texto já conhecido (27\%); indicam os livros para coleguinhas (7\%); comparam histórias vistas (7\%); reescrevem o que entenderam delas (7\%); estabelecem relações entre o texto e o seu dia-a-dia (7\%); montam outros livros (7\%) e lêem juntos, em grupo, com os amigos (7\%). É comum também, as crianças dessa idade relerem os livros (33\%).

"(...) geralmente ela conta prá mim o que ela leu, ela conta quinhentas vezes (...)" 
"(...) elas [criança e os colegas] leem; um le, conta pro outro; lêem juntos (...)"

"(...) criam, desenham, contam a respeito daquilo (...)"

Vale salientar que alguns desses comportamentos (desenhar; relacionar diferentes histórias; brincar e montar livros) só aparecem para as crianças dessa faixa etária.

Nos dados há uma forte sugestão de que o envolvimento dessa parcela da amostra com a leitura é tal que na maioria das vezes (67\%) não existe necessidade de uma situação específica para ler, e a atividade é realizada em qualquer lugar.

"Lê em qualquer lugar (...)" +

"Ah, onde ela está (...) ela abre o livro (...)"

Apenas $27 \%$ das crianças necessitam e até solicitam um ambiente calmo, silencioso para ler.

"(...) ela tem que ter uma situação mais calma, mais tranquila prá ela $\operatorname{ler}(. . .)^{n}$

'(...) ele gosta de ficar quietinho' (...) Eu quero ler, é, eu quero ler quieto prá mim entender' (...)"

\subsection{A leitura das crianças de 9 a 11 anos}

A análise dos relatos das mães de crianças de 9 a 11 anos cursando de $3^{\mathrm{a}}$ a $5^{\mathrm{a}}$ série mostra que praticamente metade (47\%) deste grupo lê com uma frequência média. Ao passo que cerca de $1 / 3(27 \%)$ lê muito e $20 \%$ pouco. Também se observa que para esse grupo a leitura vem predominantemente como uma exigência da escola (93\%). Entretanto, é necessário salientar que grande parte dessa parcela da amostra (67\%) lê por prazer, e já mostra de forma clara seleção e avaliação do material.

"Eu acho que nem, ele leu um livro o mês passado... entāo, ele se interessou, ele gostou (...) se empolgou (...) às vezes, o livro năo é muito interessante (...) termina de ler, aí porque é obrigação (...)" 
Nesta faixa etária o mais utilizado para a leitura são os livros infanto-juvenis (93\%), mas há também uma alta incidência de crianças que lêem gibi (80\%). O interesse por materiais específicos como revistas de cinema, videogame e fotonovela (lidas por $\mathbf{4 0 \%}$ deles), vem descrito pelas mães como próprio da idade. Outras leituras que chamam a atenção neste grupo são as revistas infantis ("Nosso Amiguinho" - 27\%); jornais (20\%) e palavras cruzadas (7\%).

"Revista de videogame, já comprou três (...) lê, de vez em quando alguma coisa de jornal (...) Gibi, ele adora! (...)"

Ao responderem se seus filhos realizavam alguma outra atividade a partir da leitura, as mães disseram desde que eles fazem comentários sobre o material lido (47\%), como relêem os textos (33\%); contam a história (33\%); indicam os livros (20\%); lêem para outras pessoas (20\%); pedem ajuda para entender o texto (13\%); imitam comportamentos dos personagens; escrevem; relacionam a história com o seu cotidiano ( $7 \%$ cada um).

"(...) Agora, esse livro ['O menino maluquinho'] marcou demais, ele lia toda hora, ele comentava, ele falava, ele fazia igual."

"(...) ele volta a ler trechos, ele volta a ler tudo (...)ele fala: 'Olha, o dia que vocé tiver um tempinho, le este livro que é muito bom (...)',às vezes conta prás meninas [irmás]."

Com relação à situação de leitura, quase metade dessa amostra (47\%) lê em qualquer lugar, mas a preferência por um local calmo e silencioso para realizar a atividade (53\%) está presente e sobressai a escolha do próprio quarto (27\%).

"(...) onde ela tá ela vai lendo(...)"

"Ele le sempre no quarto (...)"

\subsection{A leitura dos adolescentes de 12 a 15 anos}

Segundo a avaliação realizada pelas mães dos adolescentes que frequentam da $6^{a}$ à $8^{a}$ série, eles lêem numa frequência média $(73 \%)$ e, em geral, 
cumprindo uma exigência da escola (87\%). No entanto, um pouco menos da metade deste grupo (40\%) também lê por prazer, tendo selecionado o que gosta.

"Tem coisa que ela gosta, quando ela fica animada (...) ela pega 0 livro (...) e vai (...), mas também tem um que quando ela não gosta e que tem que ler, $\theta$ um transtorno (...)"

Além dos livros infanto-juvenis, essa parcela da amostra tem sua atenção voltada para as revistas (revistas de informação geral, notícias, moda e especializadas, por exemplo em eletrônica - 40\%). Ainda, se interessam por gibis (53\%); jornais (20\%) e outros livros (20\% - entre eles os de Aghata Christie, Paulo Coelho, Léo Buscaglia e os denominados pelas mães de romances).

"(...) ele pegou Aghata Christie para ler (...) compra livros, revistas de eletrónica (...) 'Tio Patinhas', 'Mónica', 'Cebolinha' (...) tem a 'Veja' (...) e a 'Superinteressante' (...)"

"Bastante revista, né, 'Carícia' (...), 'Pato Donald', essas coisas ela gosta (...) 'Capricho' (...)"

Estes jovens costumam desde comentar o material lido (75\%), às vezes exprimindo sua opinião sobre ele, até pedir ajuda para compreender o texto; contar as histórias; indicar os livros que leram para outras pessoas (13\% cada); ler novamente; escrever textos a partir daí; fazer relações com o cotidiano e montar objetos (7\% cada).

"Normalmente ela comenta (...) só quando o livro é bom mesmo, ela vem, me conta toda a história (...)"

"Lê, relê, vai tentar montar, tentar fazer (...)"

E interessante notar, ainda, a realização de recortes e troca de frases e gravuras dos materiais lidos entre colegas (7\%):

"(...) ela tá nessa fase da adolescência (...) recorta dizeres bonitos, algumas palavras de artista, fotografias (...) copia (...), uma escreve na agenda da outra (...) alguma coisa que leu (...)"

Predomina para este grupo, no que diz respeito à situação de leitura, a busca de um lugar tranquilo e silencioso (60\%), em geral o quarto $(40 \%)$.

"Ele se isola! (...)necéssita de silêncio (...)"

Paidéia, FFCLRP-USP, Rib. Preto, 6, Fevereiro/1994. 


\subsection{Dados que sobressaem na amostra}

Analisando o conjunto total dos dados é possível observar que o padrão de comportamento de leitura se modifica com a idade: 1) a frequência com que se lê diminui do primeiro (6 a 8 anos) para o terceiro grupo (12 a 15 anos); 2) o prazer tende a dar lugar à obrigação de acordo com o avanço da idade; 3) à medida que as crianças ficam mais velhas diminui a variedade de materiais que as atraem (de 9 no primeiro grupo para 6 no segundo e 5 no terceiro), e a de atividades que são desencadeadas pela leitura (de 13 para $10 \mathrm{e}$ para 9); 4) existe uma tendência, em função da idade, em procurar um local mais silencioso, tranquilo ou íntimo, sendo o próprio quarto o ambiente mais procurado.

\section{A participação do ambiente}

A participação do ambiente constitui-se num aspecto diretamente ligado à questão do incentivo ao hábito de leitura. As pessoas que cercam a criança ou o adolescente podem favorecer ou não tal comportamento, destacando-se a família (composta por pai, mãe e irmãos) e a escola, que mantém um contato constante e permanente e que condicionam as mais diversas vivências nessas primeiras etapas da vida.

A questão primeira que aparece para o pesquisador liga-se à necessidade de definição do que seria incentivo para o comportamento (hábito) de leitura e a esta se seguem outras que indagam sobre a participação efetiva das famílias quanto a esse comportamento das crianças e adolescentes, o sentido em que ela se processaria, a existência ou não de intenção de incentivar. 


\subsection{A participação da família nuclear}

A análise das respostas das $\mathbf{4 5}$ mães entrevistadas mostrou como primeiro dado que elas, de forma indiferenciada, consideram que estimulam o comportamento de leitura de seus filhos, tanto através de atitudes que têm o objetivo específico de fazer com que a criança leia,

"(...) às vezes ele pegava uma leitura que tinha que năo tava com muita vontade, então, eu começava a abrir a página, a ler: 'Ah, continua aqui, daqui um pouquinho eu volto', sabe? (...)"

quanto através de situações que compõem a rotina da casa e de vida da família.

"(...) Eu acho assim, o fato de eu tá lendo, porque você sabe que quando ela vê que eu tó lendo ela já quer procurar alguma coisa prá ela ler, prá ficar igual eu (...) Eu percebi que ela.se apegou leitura pelo fato de eu dizer que eu gosto de ler(...)"

Ao distinguir entre essas duas situações se observa que só $33 \%$ das mães, de fato, incentivam a leitura ${ }^{2}$, e elas o fazem de forma diversificada: $27 \%$ lendo junto com a criança;

"(...) às vezes ela tá com preguicinha, eu falo: 'Vamo lê?' Então ela vem comigo, a gente vai lendo (...)"

$20 \%$ dando o material;

"(...) resolvi comprar prá ele, justamente prá incentivar, porque ele tinha aquela dificuldade de leitura (...)"

$13 \%$ mostrando interesse pela leitura;

"(...) muitas vezes eu falo: 'Puxa! Mas que legal isso aqui.'; ou entăo, quando ele chama, eu falo: 'Ai, pera'í, eu estou lendo isso aqui, que interessante!'(...)"

$13 \%$ sugerindo ou indicando o material;

"(...) Quando eu leio um livro, eu me mostro assim, um pouco interessada, então, eu falo prá ela: 'Olha filha, esse livro 6 ótimo $(\ldots) "$

2. O pesquisador reservou a palavra incentivo para quando existe a intençăo do autor em fazer com que a criança/adolescente faça alguma atividade na direção da leitura.

Paidéia, FFCLRP-USP, Rib. Preto, 6, Fevereiro/1994. 
$7 \%$ falando para a criança ler;

"De vez em quando ele pega, le, porque eu falo: 'R., precisa ler, a tia falou que precisa ler bastante' (...)"

7\% pedindo que conte a história;

"(...) 'Você vai contar depois prá mim', entăo é uma forma dela mostrar que almente ela leu, né? (...)"

7\% lendo o material da criança para depois conversar com ela.

"(...) eu que sou a primeira a ler os livros dela prá depois passar prá ela, prá gente poder debater, conversar sobre os livros, sobre o que contou (...)"

Vale destacar o trabalho de certas famílias no criar condições para a leitura como a mãe que diz:

"(...) quando ela pede alguma coisa de papelaria, eu costumo passar em livraria (...) Ela escolhe e eu nunca neguei (...)"

ou no estabelecer contingências que "forçam" a ler.

"(...) nós demos o videogame prá ele; ficava o dia inteiro naquele aparelhinho; então nós fizemos assim: joga videogame, por exemplo, no final de semana, aí ele tem que ler um livro. Se ele ler - livro um dia, no outro dia ele pode jogar; se ele demorar uma semana, ele vai demorar uma semana prá jogar."

Quando se observa como essas atitudes de incentivo se distribuem para os 3 grupos etários (6 a 8; 9 a 11; 12 a 15 anos), tem-se uma diminuição das porcentagens $(40 \%, 33 \%, 27 \%)$ à medida que as crianças progridem na vida acadêmica.

Na tabela 3 pode-se observar a distribuição de frequência das atitudes da família que as mães avaliam como "comportamentos de incentivo", em funçāo da série escolar frequentada pela criança. 
Tabela 3 . Frequência, em função da série escolar frequentada pela criança/adolescente, com que foram relatadas as diferentes atitudes da família consideradas pelas mães como formas de incentivo à leitura dos filhos (incluindo o total de atitudes por série).

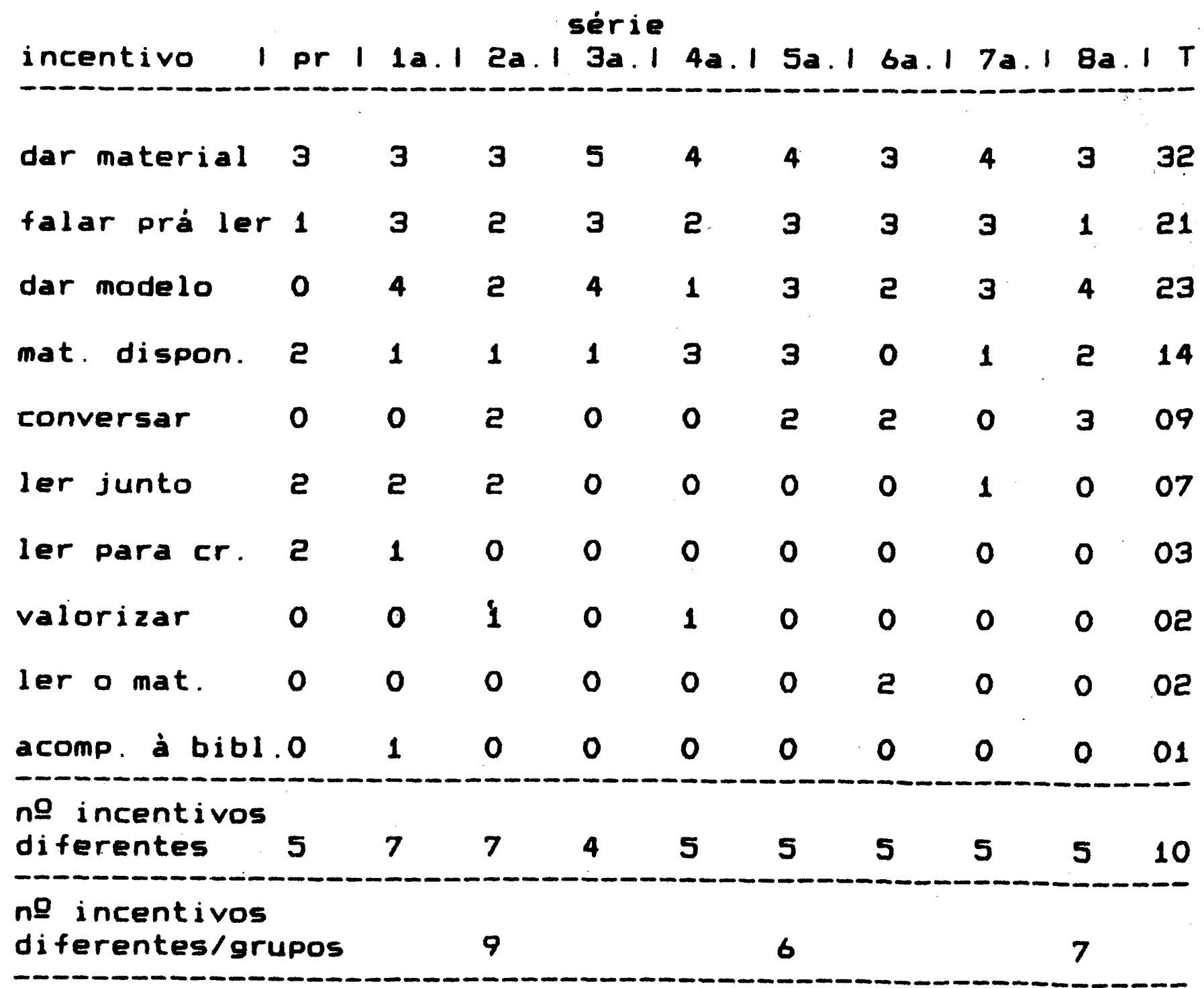

mat. dispon.- deixar material disponivel.

ler para cr. - ler para a crianca.

ler o mat. - ler o material da crianca.

acomp. à bibl. - acompanhar à biblioteca

no incentivos diferentes- quantidade de tipos diferentes de incentivo que aparece para cada série.

no incentivos diferentes/grupos- quantidade de tipos de incentivo diferentes que aparecem para cada grupo. 
Essas atitudes são variadas e destacam-se o ato de dar material para a leitura (71\%), quer sejam livros solicitados pela escola, ou escolhidos pela criança/adolescente, ou ainda, seleciónados pelas próprias mães. Em segundo lugar (51\%) é citado o fato de haver um modelo de comportamento dentro de casa, passado pelas mães ou pelos pais (que lêem com certa frequência); $47 \%$ delas fala para o filho ler, justificando de alguma forma: ou porque a escola orientou; ou explicando que teve uma vida difícil devido à falta de leitura; ou apenas lembrando-o de realizar a atividade.

Um procedimento comum $(31 \%)$ é deixar material de leitura à disposição, e às vezes com o acesso facilitado para que eles possam pegar sempre que quiserem;

"(...) o livro năo é uma coisa lá em casa que tem que ficar decorando estante e fim. O livrinho fica com ele, no quarto dele (...) Ele vai manipular a hora que ele bem entender(...)"

aparece ainda com certo destaque, conversar sobre os livros (20\%)

"(...) eu acho que d'eu ficar assim, lendo com ela (...) conversando sobre o que ela leu (...)eu acho que isso é uma forma de incentivo $(\ldots) "$

e ler junto com os filhos (16\%).

"(...) a gente tá sempre lendo junto."

Observando os resultados por outro ângulo notá-se que há recursos que mais frequentemente aparecem para o grupo das crianças mais novas, tais como: ler para a criança ou junto com ela e acompanhá-la à biblioteca. Outros são mais usados para o grupo intermediário como: dar material ou deixá-lo à disposição e falar para ler. Já, conversar sobre os livros, ler o material do filho e propiciar um modelo de comportamento são recursos mais frequentes dos pais de adolescentes. Vale salientar também que certos comportamentos são exclusivos de um ou outro grupo; assim, ler para a criança e acompanhá-la à biblioteca, só existe para as mais novas e ler o material do filho acontece para o grupo de 12 a 15 anos.

Outrossim, os dados são bem consistentes no mostrar que a variedade de recursos existentes é maior para as crianças mais novas (9 tipos diferentes), restringindo-se daí em diante (6 - 7 recursos), sugerindo que a estimulação para a leitura está mais presente quando as crianças estão nas séries iniciais da escolarização. 


\subsection{A participação da escola}

A participação da escola incentivando, dirigindo, exigindo e. cobrando leitura de seus alunos é comentada por $98 \%$ das mães entrevistadas.

Pelo relato das mães identifica-se $\mathbf{1 7}$ tipos diferentes de atividades que são propostas às crianças e adolescentes e existe certa distribuição em função das séries frequentadas, conforme mostra a tabela 4.

Tabela 4. Distribuição de frequência dos diferentes tipos de atividades propostos pela escola a partir da leitura, em função da série escolar frequentada pela criança (incluindo o número total de atividades por série).

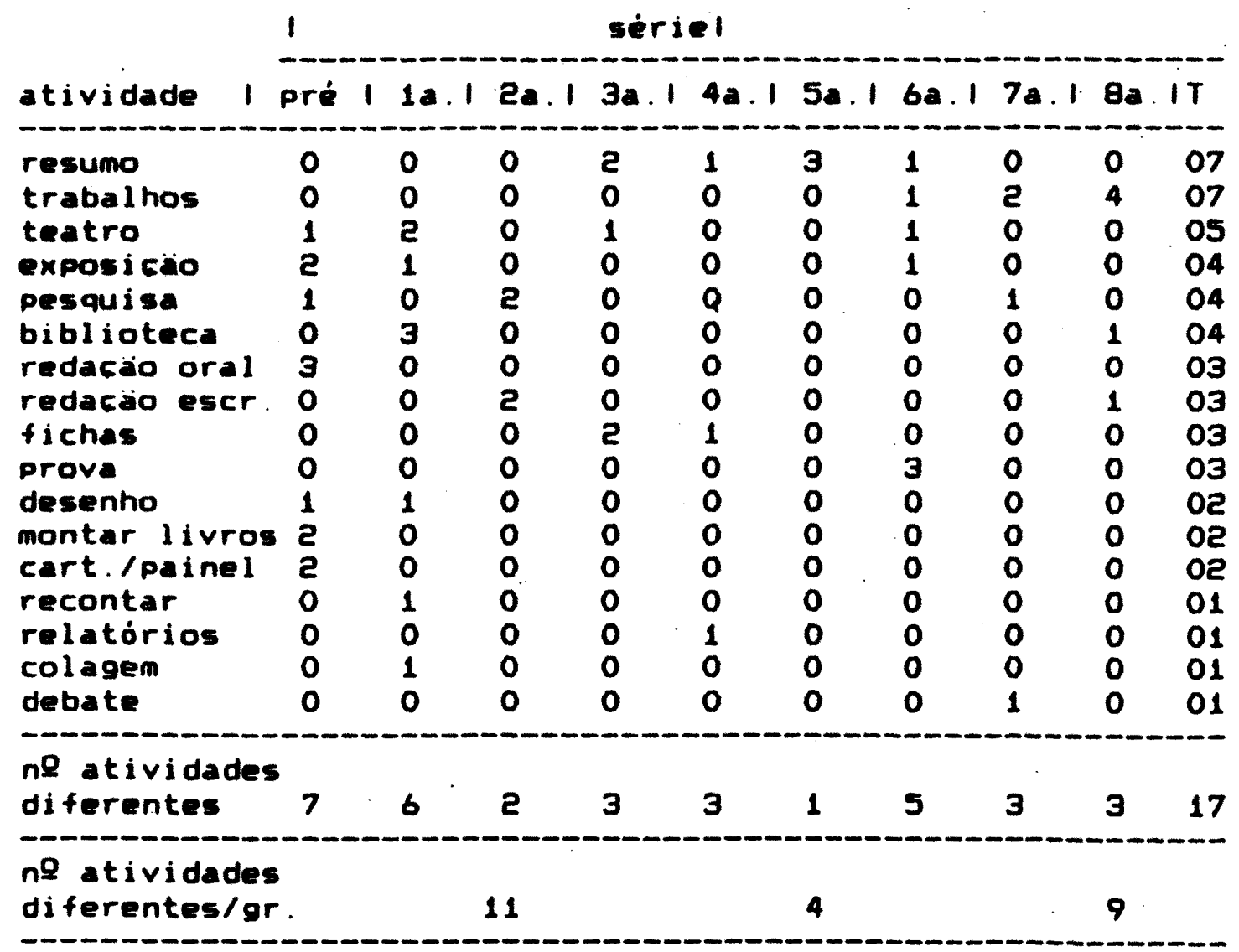

trabalhos- sem especificacajo do tipo de trabalho. exposicao- mostra de livros realizada na escola. biblioteca- visitas d biblioteca.

redacao esc. - redacäo escrita.

fichas-preenchimento de fichas de leitura.

cart. /painel-cartazes ou painel.

ng atividades diferentes- quantidade de tipos de atividades diferentes que aparece en cada série.

no atividades diferentes/or. - quantidade de tipos de atividades diferentes que aparece por grupo. 
Pode-se notar que há alguns destaques: a solicitação de que os alunos façam resumo dos livros (16\%); .

"é praxe da escola pedir o resumo do livro (...)"

a dramatização da histórias (11\%);

"(...) agora eles estāo dramatizando um livrinho (...)"

pesquisa em livros e jornais (9\%);

"(...) no colégio eles pedem, 'vocé procura alguma coisa no jornal que fale sobre isso prá gente comentar aqui na classe' (...)"

promoção de feiras de livros (9\%) e de visitas à biblioteca (9\%).

Este dado pode ser complementado com o fato de que há atividades cobradas exclusivamente para determinados grupos: de 6 a 8 anos, colagem; de 9 a 11, fazer relatórios e fichas de leitura e de 12 a 15, provas e debate.

Por outro lado, a dramatização de histórias surge como a única atividade proposta para os $\mathbf{3}$ grupos.

Apesar da porcentagem elevada de mães que dão mostras de que percebem o trabalho realizado pela escola no sentido de levar a criança a ler com frequência, apenas $57 \%$ discriminam de fato as atividades que são exigidas, ainda que o restante faça um relato geral. É bem evidente também nas respostas que as mães das crianças de 6 a 8 anos tiveram mais facilidade para especificar as solicitações da escola ( $87 \%$ contra $60 \%$ do grupo intermediário e $67 \%$ do grupo de adolescentes).

\subsection{A família extensa e os amigos}

A participação de outras pessoas da família, além dos pais e irmãos, acontece de forma bastante restrita, e nos $84 \%$ das mães entrevistadas que responderam às questōes desse tópico, a maioria (58\%) afirmou com veemência que não há colaboração de outros familiares, em nenhum sentido, com a atividade de leitura das crianças e adolescentes. 
Quando há participação ela ocorre dando o material, comentando ou fazendo perguntas sobre os livros, fornecendo um modelo de comportamento de leitura, lendo, indicando e contando histórias.

Também, algumas crianças/adolescentes ganham livros de amigos (9\%), entretanto, isto não é descrito como uma forte influência, mas como algo esporádico que tem predominantemente o objetivo de presentear.

\section{DISCUSSÃO}

Se se busca sintetizar os dados tem-se que quando descobrem as letras e aprendem a decifrá-las, as crianças se envolvem com uma diversidade grande de material literário e também com um número elevado de atividades, individuais ou em grupo, que são desencadeadas pela leitura. Passado esse primeiro momento, elas se tornam críticas e começam a selecionar seus livros, gibis, revistas... e, diminui a variedade do que fazem a partir das leituras. $\mathrm{Na}$ adolescência, buscam no que lêem o que lhes interessa e depois seus atos são cada vez mais intimistas (escrever, refletir sobre o seu cotidiano). A leitura se torna algo de que se pode lançar mão quando necessário, para conseguir uma informação, para se manter atualizado.

Durante todo este trajeto, crianças e adolescentes são acompanhados de perto pela escola e pela família. primeira cabe a responsabilidade de promover a habilidade de leitura e de fazer com que ela se efetive, e à segunda de prover condições para que a criança leia.

Pode-se deduzir dos relatos das mães que a escola acaba impondo à familia suas orientaçōes porque parte dela a solicitação de leitura; ela escolhe e os pais têm que adquirir o material, cuidando para que os filhos cumpram as tarefas acadêmicas, acatando a autoridade escolar.

Esta situação pode ser vista de um outro ângulo: a re-socialização dos pais que se vêem obrigados a aprender e utilizar novas práticas para dar conta de apoiar o desenvolvimento de suas crianças e adolescentes; ou seja, entre outras competências, eles precisam se capacitar para ajudar na montagem de uma dramatização, na confecção de cartazes; ter noção de como se faz uma ficha de livro; ler o material da criança pára poder esclarecer dúvidas. 
Se se volta a atenção para as crianças e adolescentes, muitos dos seus comportamentos que são desencadeados pela leitura, apesar de ocorrerem de forma espontânea, foram aprendidos na escola. Ao solicitar a leitura e fazer cobranças, ela acaba ensinando um repertório de atividades que podem ser realizadas; o aluno internaliza esse conjunto de possibilidades e passa a apresentá-lo quando lhe apraz. Mas, é fundamental não esquecer que, nessa mesma direção, existe também a influência da família: se ela tem leitores, provavelmente, "ensina" uma série de outras atitudes diante da leitura.

De outro lado, chama atenção nos dados o fato de que, gradativamente, à medida em que as crianças ficam mais velhas, o prazer vai cedendo lugar à obrigação. De certa forma, este movimento é acompanhado por outro que indica uma linha evolutiva em que inicialmente são propostas leituras e atividades nas quais predomina o lúdico e que envolvem, com frequência, uma necessidade de cooperação com o adulto. Posteriormente, para as crianças pouco mais velhas, começam a ser solicitadas atividades mais solitárias, como o resumo, as fichas de livros, abandonando-se paulatinamente o lúdico, até que aos adolescentes sejam feitas propostas predominantemente individuais e que exigem maior elaboração.

Parece que as solicitações vinculadas com a leitura acompanham o próprio desenvolvimento, e se caminha da utilização do lúdico para exigências de debate e reflexão.

Outro aspecto relevante no discurso das mães é que, independente da idade, a leitura leva a outros comportamentos que envolvem algum tipo de contato social: fazer comentários; contar a história; indicar livros ou, pedir ajuda para desvendar o texto. Assim, parece que a atividade de ler, ainda que realizada predominantemente de forma solitária, mantém a possibilidade de realizar uma série de contatos, e poder-se-ia dizer que ela cria condições para um encontro: seja do leitor com o texto, com o autor, com pessoas, com personagens, ou ainda consigo mesmo.

Quando Proust (1991) descreve a sua relação com o livro na infância, ele conta que iniciada a leitura, ela tornava-se mais importante que tudo na vida e que o livro ia com ele para onde quer que ele fosse, deixando claro que o material assumia o papel de companheiro do qual ele só se separava no final e com tristeza.

Era por meio deste "amigo" que ele se aproximava dos escritores e via despertado o desejo de conhecer aquilo que muitas vezes o autor deixava de 
dizer. Além disso - Proust vai além - ele podia entrar na história e viver com os personagens todas as experiências deles, dando-lhes, ainda que por um tempo limitado, mais atenção e afeto do que às "pessoas da vida".

Nessa direção, é importante que se retome e enfatize as idéias expressas por Cunha (1993) de que a leitura tem o poder de funcionar "como uma forma de socialização secundária" pelo fato de levar à interiorização de valores ou ao seu reforço; assim, enquanto socializadores tanto a escola como a familia fazem do livro um agente, trocando idéias e experiências.

Tudo isto reforça a noção de que a atividade de leitura das crianças e adolescentes deve ser observada e orientada com muito cuidado pois, se como diz Cunha (1993), as narrativas apresentam-se repletas de valores, modelos de comportamento, idéias, então, elas devem ser capazes de conduzir o leitor a uma nova compreensão de si mesmo e do mundo, redirecionando o processo de sua socialização.

Por outro lado, dir-se-ia que os dados contrariam a percepção vigente de que existe uma crise de leitura (Wornicov, 1986; Perrotti, 1990; Staiger, 1990) - pelo menos entre a classe média - e acentuam o fato de que essa idéia vem muito mais de uma quebra nas expectativas dos adultos quanto à atividade de ler das crianças e adolescentes do que do fato deles não lerem, porque os dados mostram que há uma frequência grande de leitura entre eles.

\section{REFERÊNCIAS BIBLIOGRAFICAS}

ABRAMOVICH, F. O estranho mundo que se mostra as crianças. 5.ed. São Paulo, Summus, 1983.

. A literatura infantil: gostosuras e bobices. São Paulo, Scipioni, 1990.

BIASOLI-ALVES, Z. M. M. \& DIAS DA SILVA, M. H. G. F. Análise qualitativa de dados de entrevista: uma proposta. Paidéia, n.2, p. 61-67, 1992.

CADERMATORI, L. O que é literatura infantil. 3.ed. São Paulo, Brasiliense, 1987.

CARVALHO, B. V. DE. Compêndio de literatura infantil. São Paulo, IBEP, s/d. 
CUNHA, M. T. S. Biblioteca das moças: contos de fada ou contos de vida? Cadernos de Pesquisa, n. 85, p. 54.62, mai. 1993.

PERROTTI, E. Confinamento cultural, infância e leitura. São Paulo, Summus, 1990.

PROUST, M. Sobre a leitura. 2 ed. Campinas, Pontes, 1991.

SILVA, E. T. DA. Leitura na escola e na biblioteca. 2.ed. Campinas, Papirus, 1986.

WORNICOV, R. (et al.). Criança - leitura - livro. São Paulo, Nobel, 1986.

ZILBERMAN, R.; LAJOLO, M. Um Brasil para crianças: Para conhecer a literatura infantil brasileira: histórias, autores e textos. São Paulo, Global, 1986.

\section{ABSTRACT}

\section{(THE CHILDREN'S AND ADOLESCENTS' READING BEHAVIOR, ACCORDING TO THE MOTHERS' CONCEPTION)}

This research was structured in order to describe the view that adults have of children's and adolescents' reading behavior, including: what they read, the reasons that motivate their reading, the participation of the social environment.

For this, 45 mothers were interviewed whose children went to private elementary schools, according to the "Roteiro para Investigação do Comportamento de Leitura" (Guide to Reading Behavior Investigation). The interviews were carried out in the mothers' houses, recorded and later fully transcribed, and the data were submitted to qualitative analysis.

The analysis of the reports shows that: 1) As a whole, children and adolescents read with frequency, in most cases to fulfill the school's reading assignments; their reading generates other activities which include story-telling, making comments and asking for help in comprehension problems; books and magazines for children and adolescents are the reading materials that are the 
most mentioned. 2) The family usually foster the activity in different ways, such as shared reading and the indication and supply of books, magazines, etc.

The discussion includes a reflection on the family and scholl participation in the children's and adolescents' reading behavior and also on the influence of the activity in the socialization process.

Key words: reading behavior; children and adolescents; human development; education.

Palavras chaves: comportamento de leitura; crianças e adolescentes; desenvolvimento humano; educação. 